\title{
Effects of caudal block with mepivacaine on resting ventilation and ventilatory response to carbon dioxide in sedated children
}

\begin{abstract}
We examined the effects of caudal anaesthesia using $10 \mathrm{mg} \cdot \mathrm{kg}^{-1}$ of one or two per cent mepivacaine without epinephrine on resting ventilation, arterial blood gas tensions and the ventilatory response to carbon dioxide in 27 sedated children. Expired minute volume and respiratory frequency decreased significantly after the caudal blocks in both groups. $\mathrm{PaO}_{2}$ and $\mathrm{PaCO}_{2} \mathrm{re}$ mained unctranged in both groups. The slope of the $\mathrm{CO}_{2}$ response curve increased significantly in both groups. The mean plasma mepivacaine levels were $4.6 \pm 1.6(5 D)$ and $4.6 \pm 1.0 \mathrm{\mu g} \cdot \mathrm{ml}^{-1}$ 20 minutes after the caudal blocks with one and wo per cent mepivacaine, respectively. These results demonstrate that resting ventilation is impaired but the venitatory response to carbon dioxide is improved similarly by caudal block with one or two per cent mepivacaine.
\end{abstract}

\section{Key words}

ANAESTHETIC, LOCAL: mepivacaine; ANAESTHETIC TECHNIQUE: caudal, epidural; VENTILATION; paediatric, carbon dioxide response.

From the Department of Anesthesiology, Shimane Medical University, Izumo, Japan.

Address correspondence to: Dr. M. Takasaki, Department of Anesthesiology, Miyazaki Medical University, Kiyotake, 889-16, Japan.
Caudal anaesthesia has been used for surgery and postoperative pain relief in children.' However, little is known of the effect of caudal anaesthesia on respiratory function. Recently, we demonstrated a marked improvement in the ventilatory response to carbon dioxide following caudal block with lidocaine or bupivacaine. ${ }^{2}$ We also showed a slight impaiment of resting ventilation foliowing caudal block with $10 \mathrm{mg} \cdot \mathrm{kg}^{-1}$ of 1.5 per cent lidocaine. However, no data are available concerning caudal epidural administration of mepivacaine in children.

The effect of caudal block with lidocaine or bupivacaine on the $\mathrm{CO}_{2}$ response is due to a systemic stimulating effect on the ventilatory control mechanism of lidocaine or bupivacaine absorbed into the bloodstream from the caudal epidural space. ${ }^{3.4}$ The effect of caudal block with lidocaine on resting ventilation is due either to the peripheral nerve block or to the systemic effect of lidocaine on the respiratory centre, chemoreceptors or myoneural junction. ${ }^{5}$

The present study was designed to compare the ventilatory effects of caudal blocks with one and two per cent mepivacaine, and to determine whether caudal epidural mepivacaine alters the slope of the $\mathrm{CO}_{2}$ response curve, as do lidocaine and bupivacaine.

\section{Methods}

\section{Patients}

The study was approved by our institution's human research review committee and parental consent was obtained for each patient. Twenty-seven patients scheduled for elective minor paediatric surgery under caudal anaesthesia, weighing between 9 and $18 \mathrm{~kg}$, were selected for this study. Their ages ranged from one to six years. All were free from cardiorespiratory disease. Children were randomly divided into three groups: ten children in Groups I and II received one and two per cent mepivacaine solution without epinephrine in the caudal epidural 
space, respectively, and six children in Group III received no drug throughout this study.

\section{Caudal block}

All children were premedicated with $6-7 \mathrm{mg} \cdot \mathrm{kg}^{\prime \prime}$ of secobarbitone, not exceeding $100 \mathrm{mg}, 0.5 \mathrm{mg} \cdot \mathrm{kg}^{-1}$ of pentazocine and $0.01 \mathrm{mg} \cdot \mathrm{kg}^{-1}$ of atropine $\mathrm{IM}$, one hour before induction of anaesthesia. General anaesthesia was induced with $0.5-1.5$ per cent halothane, nitrous oxide and oxygen by mask, for placement of an intravenous cannula and the caudal epidural catheter. The intravenous cannula was placed in a vein on the back of a hand and a mixture of five per cent dextrose in water and lactated Ringer's solution was administered at a rate of $5 \mathrm{ml} \cdot \mathrm{kg}^{-1} \cdot \mathrm{hr}^{-1}$.

Each patient was placed in a lateral decubitus position for the caudal block. After skin preparation and draping, a 18-gauge disposable needle (Terumo) was inserted in the sacral canal and an epidural catheter (Portex) was inserted through the needle. Following removal of the needle, the child was turned supine and $0.5 \mathrm{ml}$ of one per cent lidocaine without epinephrine was injected intradcrmally and subcutaneously for painless puncture of the femoral artery, after which the inhalation anaesthetics were discontinued.

After a resting period of 20 minutes and the bascline measurements for ten minutes, caudal analgesia was produced by injection of $10 \mathrm{mg} \cdot \mathrm{kg}^{-1}$ of one or two per cent mepivacaine without epinephrine. The dosage given was determined in a previous study, ${ }^{6}$ to obtain an anaigesic level up to $T_{10}$. A test dose was not used in this study. Thirty minutes after caudal injection, as all measurements were finished, the spread of cutaneous analgesia was observed by pin-prick testing. ${ }^{\text {" }}$

\section{Measurements}

Arterial blood samples were taken by direct puncture from the femoral artery into heparinized disposable syringes (Terumo) before and 20 minutes after caudal injection in Groups I and II, or at control and 30 minutes later in Group III. Immediately after sampling, $\mathrm{PaO}_{2}$ and $\mathrm{PaCO}_{2}$ were determined using a blood-gas analyzer (Radiometer ABL3). The results were not corrected for body temperature.

After each arterial puncture, measurements of tespiratory frequency (f), expired minute volume ( $\left.\dot{V}_{E}\right)$ and end-tidal $\mathrm{CO}_{2}$ concentration were made during room-air breathing and continued for three minutes. $\dot{V}_{E}$ was measured using a mask (dead space volume, $15 \mathrm{mi}$ ) and a small transducer (dead space volume, $10 \mathrm{ml}$ ) connected to a hot-wire respiratory flowmeter (Minato Medical Science, Respiromonitor RM-200). ${ }^{\gamma}$ This had been calibrated with $100-\mathrm{ml}$ and $1000-\mathrm{ml}$ plastic syringes of air.
TABLE I Patient characteristics

\begin{tabular}{lllll}
\hline Group & $\begin{array}{l}\text { Number of } \\
\text { patients }\end{array}$ & $\begin{array}{l}\text { Age } \\
(y \mathrm{r})\end{array}$ & $\begin{array}{l}\text { Weight } \\
(\mathrm{kg})\end{array}$ & $\begin{array}{l}\text { Height } \\
(\mathrm{cm})\end{array}$ \\
\hline I: $1 \%$ mepivacaine & 10 & $3.1 \pm 0.9$ & $14.0 \pm 1.8$ & $96 \pm 7$ \\
II: $2 \%$ mepivacaine & 10 & $3.0 \pm 1.5$ & $13.7 \pm 2.8$ & $94 \pm 11$ \\
III: Control & 7 & $3.0 \pm 1.3$ & $13.9 \pm 2.3$ & $94 \pm 9$ \\
\hline
\end{tabular}

Values are mean $\pm S D$.

End-tidal $\mathrm{CO}_{2}$ concentration was measured using a $\mathrm{CO}_{2}$ analyzer (Datex, Normocap), which was calibrated before each measurement with two different gases. All signals were displayed on a 4-channel recorder (San-Ei, Rectigraph $8 \mathrm{~K}$ ). Tidal volume (VT) was derived from the measured values of $f$ and $\dot{V}_{E}$. The volumes were expressed in BTPS. End-tidal $\mathrm{CO}_{2}$ partial pressure $\left(\mathrm{PETCO}_{2}\right)$ was calculated from the measured end-tidal $\mathrm{CO}_{2}$ concentration.

Following each measurement of resting ventilation, a $\mathrm{CO}_{2}$ stimulation test was performed by the Read's rebreathing method. ${ }^{8}$ Each patient rebreathed exhaled $\mathrm{CO}_{2}$ through a two-way breathing valve attached to a oneor two-litre reservoir, initially filled with seven per cent $\mathrm{CO}_{2}$ in $\mathrm{O}_{2}$. Oxygen was added to maintain a constant volume in the rebreathing apparatus. Rebreathing was continued until end-tidal $\mathrm{CO}_{2}$ concentration increased to nine per cent, which was usually achieved within four minutes. The slope of the $\mathrm{CO}_{2}$ response curve was calculated at high $\mathrm{PETCO}_{2}(60 \mathrm{mmHg})$ for each subject and expressed as $\triangle V_{E}$ per $\triangle \mathrm{PETCO}$ -

All measurements were made with quietly sedated patients in a supine position before the start of surgery. Plasma mepivacaine levels were determined by gas chromatography, ${ }^{6}$ using arterial blood samples taken for blood-gas analysis.

\section{Anaesthesia during surgery}

After all investigations had been performed, a suitable dose of 1.5 per cent mepivacaine without epinephrine was administered through the caudal epidural catheter and surgery was performed. The patient was managed with intravenous administration of $2-3 \mathrm{mg} \cdot \mathrm{kg}^{-1}$ of thiamylal or inhalational administration of nitrous oxide, oxygen and a low concentration of halothane by mask. Electrocardiogram, heart rate, and rectal temperature were monitored, and arterial pressure was measured throughout the operation in all the children.

\section{Statistical analysis}

The data obtained before and during caudal block in Groups I and II or obtained at control and 30 minutes later in Group III were analyzed by repeated measures analysis of variance (ANOVA). Comparisons among the three 
TABLE II Resting ventilation, arterial blood-gas tensions and the ventilatory response to carbon dioxide before and during caudal block with one or two per cent mepivacaine, and during control without block in sedated children

\begin{tabular}{|c|c|c|c|c|c|c|}
\hline & \multicolumn{2}{|c|}{ Group I (1\% mepivacuine) } & \multicolumn{2}{|c|}{ Group II (2\% mepivacuine) } & \multicolumn{2}{|c|}{ Group III (Controt) } \\
\hline & $\begin{array}{l}\text { Before } \\
\text { candal }\end{array}$ & $\begin{array}{l}\text { During } \\
\text { coudal }\end{array}$ & $\begin{array}{l}\text { Before } \\
\text { caudal }\end{array}$ & $\begin{array}{l}\text { During } \\
\text { caudal }\end{array}$ & Control & $30 \mathrm{~min}$ \\
\hline$f\left(\min ^{-1}\right)$ & $20.9 \pm 3.4$ & $17.6 \div 2.7 \ddagger \ddagger$ & $20.7 \pm 2.3$ & $18.6 \pm 1.7 \pm \pm$ & $20.0 \pm 2.6$ & $19.3 \pm 2.4$ \\
\hline $\mathrm{VI}\left(\mathrm{ml} \cdot \mathrm{kg}^{-1}\right)$ & $9.9 \pm 1.3$ & $10.7 \pm 1.2$ & $8.8 \pm 1.5$ & $9.0 \pm 1.5$ & $10.6 \pm 1.7$ & $10.8 \pm 1.5$ \\
\hline$V_{E}\left(\mathrm{ml} \cdot m i n^{-1}-\mathrm{kg}^{-1}\right)$ & $206 \pm 22$ & $188=15+t$ & $184 \pm 43$ & $168 \pm 31 \neq \ddagger$ & $209 \pm 34$ & $207 \pm 37$ \\
\hline $\begin{array}{l}\mathrm{PETCO}_{2}(\mathrm{mmH}) \\
\Delta \mathrm{VE} / \triangle \mathrm{PETCO}_{2}\end{array}$ & $41.1 \pm 3.4$ & $41.0 \pm 4.0$ & $38.4 \pm 2.4$ & $39.5 \pm 2.0 \dagger \ddagger$ & $41.3 \pm 2.0$ & $41.2 \pm 1.9$ \\
\hline$\left(\mathrm{ml} \cdot \mathrm{min}^{-1} \cdot \mathrm{kg}^{-1} \cdot \mathrm{mmHg}^{-1}\right)$ & $45.5 \pm 25.2$ & $62.8 \pm 30.5 \dagger \ddagger$ & $45.0 \pm 20.3$ & $67.2 \pm 26.8 * \pm$ & $35.9 \pm 9.1$ & $36.3 \pm 13.0$ \\
\hline $\mathrm{PaCO}_{2}(\mathrm{mmHg})$ & $44.9 \pm 1.5$ & $45.0 \div 1.9$ & $41.9 \pm 2.2$ & $42.9 \pm 2.2$ & $45.0 \pm 1.8$ & $44.2 \pm 1.3$ \\
\hline $\mathrm{PaO}_{2}(\mathrm{mmHg})$ & $90.4 \pm 14.2$ & $90.0 \pm 9.4$ & $92.5 \pm 9.9$ & $95.6 \pm 6.0$ & $93.9 \pm 2.8$ & $98.7 \pm 3.7$ \\
\hline
\end{tabular}

Abbreviations: $f$, respiratory frequency; $\mathrm{VT}$, tidal volume; $\mathrm{V} \mathrm{E}_{\text {; }}$ expired minute volume; $\mathrm{PETCO}_{2}$, end-tidal $\mathrm{CO}_{2}$ partial pressure.

Values are means $\pm \mathrm{SD}$.

*Significant difference from values before caudal anaesthesia, $p<0.05$.

† Significant difference from values before caudal anaesthesia, $\mathrm{p}<0.01$

$\$$ Significant difference from changes of the control group, $p<0.05$.

groups employed one-way ANOVA. Multiple pairwise comparisons between the groups were assessed by the test with Bonferroni correction. $P<0.05$ was considered significant. All results are expressed as mean $\pm \mathrm{SD}$.

\section{Results}

Patient characteristics are summarized in Table I and all the data for the three groups are reported in Table Il. There were no significant differences in patient characteristics or baseline ventilatory and blood-gas values among the three groups. The mean upper levels of analgesia obtained 30 minutes after caudal injection were $T_{6.6 \pm 2.1}$ in Group I and $T_{7.6 \pm 2.1}$ in Group II.

$\forall E$ and $f$ decreased significantly after the caudal blocks. Mean VE decreased by nine per cent in Groups I and II. Mean $f$ decreased by 16 per cent in Group $I$ and ten per cent in Group II. These changes in VE and $f$ in Groups I and II were significantly greater than those in Group III. $V T$ did not change in either group. In Group III, $\hat{V}_{E}, f$ and $V T$ stayed unchanged. $\mathrm{PETCO}_{2}$ and $\mathrm{PaCO}_{2}$ reruained unchanged in Groups $\mathrm{I}$ and III but $\mathrm{PETCO}_{2}$ increased significantly in Group $\mathrm{HI}$. $\mathrm{PaO}_{2}$ remained unchanged in each group.

The mean slope $(\Delta \dot{V} \mathrm{E} / \Delta \mathrm{PETCO})$ of the $\mathrm{CO}_{2}$ response curve increased significantly following caudal blocks with mepivacaine, in Group I by 38 per cent and in Group II by 49 per cent, but there was no significant difference between the two groups. In Group III, there was no change in the slope. The changes in the slope in Groups I and II were significantly greater than that in Group III.

The mean plasma levels of mepivacaine were $4.6 \pm 1.6$ and $4.6 \pm 1.0 \mu \mathrm{g} \cdot \mathrm{ml}^{-1}$ in Groups $\mathrm{I}$ and $\mathrm{II}$, respectively, 20 minutes after caudal injection. There was no correla- tion between the plasma levels and the changes in the slope of the ventilatory response to $\mathrm{CO}_{2}$.

\section{Discussion}

The present study shows that resting ventilation is impaired but the ventilatory response to $\mathrm{CO}_{2}$ is improved by caudal block with one or two per cent mepivacaine. The use of this block is not precluded by the impaiment of resting ventilation, because reductions of $\dot{V}_{E}$ were only nine per cent of control values. Although a significant increase in $\mathrm{PETCO}_{2}$ was observed in Group II, the mean increase in $\mathrm{PFTCO}_{2}$ of $1.1 \mathrm{mmHg}$ was very small and of no clinical significance. The improvement in the ventilatory response to $\mathrm{CO}_{2}$ is favorable in the use of this block, especially in sedated children.

There is only one report showing the effect of caudal anaesthesia on respiratory function in children, apart from our previous report. ${ }^{2}$ Hatch et al. ${ }^{9}$ showed that caudal block with bupivacaine during halothane anaesthesia reduces the influence of surgical stimulus and hence reduces respiratory frequency, but have not shown a direct effect of caudal block on ventilation. In our previous study, ${ }^{2}$ mean $\mathrm{VE}$ decreased by nine per cent following caudal block with $10 \mathrm{mg} \cdot \mathrm{kg}^{-1}$ of 1.5 per cent lidocaine and by eight per cent following caudal block with $3.3 \mathrm{mg} \cdot \mathrm{kg}^{-1}$ of 0.5 per cent bupivacaine. The reductions in $\dot{V E}$ following caudal epidural injections of mepivacaine and other local anaesthetics are similar. The increase in the slope of the $\mathrm{CO}_{2}$ response curve following caudal epidural injection of mepivacaine is also similar to that seen with lidocaine or bupivacaine. ${ }^{2}$

The impairment of resting ventilation following caudal block is due either to peripheral sensory and motor block 
or to the systemic depressant effects of local anaesthetics on the respiratory control centre in the mid-brain, on chemoreceptors in medulla and carotid bodies, ${ }^{5}$ or on neuromuscular transmission. ${ }^{10}$ In this study, the mean upper level of cutaneous analgesia was $T_{6.6}$ in Group I and $\mathbf{T}_{7.6}$ in Group II. Deafferentation of the abdomen and lower chest wall leads to a reduction of sensory input to the respiratory motor nuclei and consequently to reduced motor output. ${ }^{11}$ Furthermore, incomplete peripheral motor nerve block of lower chest wall would be present, although the level and the degree of spinal motor nerve block are unknown. Afferent and efferent nerve blocks would be a main cause of the impairment of resting ventilation.

The direct depressant effect of absorbed mepivacaine on the respiratory centre is unclear. Although Nishino et at. ${ }^{12}$ have shown that phrenic nerve activity is depressed by the rapid injection of $2 \mathrm{mg} \cdot \mathrm{kg}^{-1}$ of lidocaine in cats, this effect may result from a reduction of sensory input to the respiratory centre from depressed chemoreceptors. They noted that a subconvulsive dose of lidocaine can produce excitatory activity in various areas of the brain. The improvement in the ventilatory response to $\mathrm{CO}_{2}$ is the result of a stimulation of the central activity induced by absorbed mepivacaine. The mean plasma mepivacaine level of $4.6 \mu \mathrm{g} \cdot \mathrm{ml}^{-1}$ seen in this study should be high enough to stimulate central activity. The systemic effect of local anaesthetics on the control of ventilation has been reported in awake adults. Intravenous or epidural lidocaine increases the slope of the $\mathrm{CO}_{2}$ response curve. ${ }^{3.13}$ Bupivacaine also increases the slope. ${ }^{4}$ Although Labaille et $a .^{3}$ and Negre et al. ${ }^{4}$ reported that an increasing plasma lidocaine or bupivacaine level increased the slope of the $\mathrm{CO}_{2}$ response curve, in this study no correlation between the plasma mepivacaine levels and the changes in the slope was found.

This study was made with heavily sedated children premedicated with secobarbitone and pentazocine. However, during the course of the study, no fluctuation of pulmonary ventilation and the ventilatory response to $\mathrm{CO}_{2}$ was found, as seen in Group III. Caudal anaesthesia is ordinarily used in sedated children in surgical practice. Therefore, the results obtained in this study are clinically relevant. The doses of mepivacaine used and the blood levels obtained in this study were high, but no patient had signs of local anaesthetic toxicity under sedated conditions. These doses are necessary to obtain a satisfactory block for surgery such as inguinal herniorrhaphy or orchiopexy. ${ }^{14-16}$ In the present study a test dose was not used, but in clinical practice a test dose of $1 \mathrm{ml}$ of local anaesthetics should be given. ${ }^{1}$ Methodological considerations for measurements and patient conditions were discussed in our previous report. ${ }^{2}$

\section{References}

1 Arthur DS, MCNicol LR. Local anaesthetic techniqucs in paediatric surgery. Br J Anaesth 1986; 58: 760-78.

2 Takasaki $M$. Ventilation and ventilatory response to carbon dioxide during caudal anaesthesia with lidocaine or bupivacaine in sedated children. Acta Anaesthesiol Scand. 1988; 32: $218-21$

3 Labaille T, Clergue F, Samii K, Ecoffey C. Berdeaux A. Ventilatory response to $\mathrm{CO}_{2}$ following intravenous and epidural lidocaine. Anesthesiology 1985; 63: 521-5.

4 Negre I, Labaille $T$, Samii $K$, Noviant $Y$. Ventilatory response to $\mathrm{CO}_{2}$ following axillary blockade with bupiva caine. Anesthesiology 1985; 63: 401-3.

5 Cousins $M J$. Epidural neural blockade. In: Cousins MJ, Bridenbaugh PO (Eds). Neural blockade in clinical anesthesia and management of pain. Philadclphia: JB Lippincott, 1980: 176-274

6 Takasaki $M$. Blood concentrations of lidocaine, mepivacaine and bupivacaine during caudal analgesia in children. Acta Anaesthesiol Scand 1984; 28: 211-4.

7 Yoshiya I, Shimada $Y$, Tanaka $K$. Evaluation of a hot-wire respiratory flowmeter for clinical applicability. J Appl Physiol 1979; 47: 1131-5.

8 Read DJC. A clinical method for assessing the ventilatory response to carbon dioxide. Aust Ann Med 1967; 16: 20-32.

9 Hatch DJ, Hulse MG, Lindahl SGE. Caudal analgesia in children: influence on ventilatory cfficiency during halothane anaesthesia. Anaesthesia 1984; 39: 873-8.

10 Telivuo $L$. Effects of intra-arterial mepivacaine and bupivacaine on neuromuscular transmission: in man. Acta Anaesthesiol Scand 1967; 11: 327-32.

11 Bromage PR. Epidural analgesia. Philadelphia: WB Saunders, 1978: 400 .

12 Nishino T, Yonezawa T, Honda Y. Different laryngeal responses during respiratory arrest produced by hypoxia withdrawal, thiopentone, ketamine, and lidocaine in cats. Anesthesiology 1982; 56: 280-5.

13 Gross JB, Caldwell CB, Shaw LM, Lauchs SO. The effect of lidocaine on the ventilatory response to carbon dioxide. Anesthesiology 1983; 59: 521-5.

14 Takasaki M, Dohi S, Kawabata Y, Takahashi T. Dosage of lidocaine for caudal anesthesia in infants and children. Anesthesiology $1977 ; 47: 527-9$.

15 Armitage EN. Caudal block in children Anaesthesia 1979; 34: 396.

$16 M c G o w n$ RG. Caudal analgesia in children: five hundred cases for procedures below the diaphragm. Anaesthesia 1982; 37: 806-18. 


\section{Résumé}

On a étudié les effets de l'anesthésie caudale utilisant $10 \mathrm{mg} \cdot \mathrm{kg}^{-1}$ de un ou deux pour cent de mépivacaüne sans épinéphrine sur ia ventilation au repos, la gazométrie artériclle et la rêponse ventilatoire au $\mathrm{CO}_{2}$ chez 27 enfants sous sédation. Le volume minute expiré et la fréquence respiratoire diminuèrent signiffcativement après le bloc caudal avec les deux concentrations. $\mathrm{La} \mathrm{PaO}_{2}$ et la $\mathrm{PaCO}_{2}$ demeurèrent inchangées dans les deur groupes. La pente de la courbe réponse au $\mathrm{CO}_{2}$ augmenta significarivement après le bloc caudal aux deux concentrations. Les taux moyens plasmatiques de mépivacaine étaient de $4.6 \pm 1.6(S D)$ et $4.6 \pm 1.0 \mu \mathrm{g} \cdot \mathrm{ml}^{-1} 20$ minutes après le bloc caudal avec un et deux pour cent de mépivacaine respectivement. Les résultats démontrent que la ventilation au repos est aitérée mais la réponse ventilatoire au $\mathrm{CO}_{2}$ est améliorée après bloc caudal avec un et deux pour ceni de mépivacaïne. 